\title{
Endodontic Management of a Three Rooted Mandibular Third Molar with a Dilacerated Distal Root and Close Approximation to the Inferior Alveolar Canal: A Case Report
}

\author{
Wael Waheed Sharawy ${ }^{1}$, Hany Mohamed Aly Ahmed² \\ ${ }^{1}$ Primary Health Care Corporation, Oral Health Division, Doha, Qatar \\ 2 University of Malaya, Faculty of Dentistry, Department of Restorative Dentistry, Kuala Lumpur, Malaysia
}

\section{Correspondence:}

Dr. Wael Waheed Sharawy

Primary Health Care Corporation, Oral Health Division, Doha, Qatar

e-mail: wael.waheed@ymail.com

Received 1 August 2017

Accepted 29 August 2017

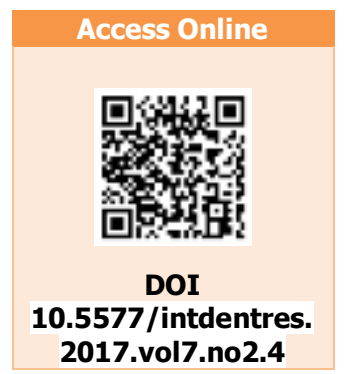

\section{Introduction}

Most posterior location and abnormal eruption patterns of third molar teeth are common reasons for many dental complications (1). That's why their extraction remains the treatment of choice for many 45.

\begin{abstract}
Aim: A thorough understanding of root and canal anatomical variations is essential for achieving successful endodontic treatment. Literature continues to demonstrate complex root and canal anatomical variations in mandibular third molars which are sometimes in close approximation to the inferior alveolar canal.

Methodology: A 26-year-old male patient was referred for endodontic treatment of a three-rooted mandibular third molar with a dilacerated distal root and close approximation to the inferior alveolar canal. A cone beam computed tomography was performed to assess the root and canal anatomical variations together with the inferior alveolar canal. Conventional endodontic treatment was performed using a rotary nickel-titanium file system, and the canals were then obturated using a cold lateral condensation technique.

Results: The endodontic treatment procedures were performed successfully and in the follow-up visit, the tooth was asymptomatic.

Conclusions: Despite limited accessibility and challenges during root canal treatment procedures, retaining every functional component of the dental arch, including mandibular third molars, is an essential goal of contemporary dental practice.
\end{abstract}

Keywords: Dilaceration, inferior alveolar canal, mandibular third molar, root canal treatment

How to cite this article: Sharawy WW, Ahmed HMA. Endodontic management of a three rooted mandibular third molar with a dilacerated distal root and close approximation to the inferior alveolar canal: A case report. Int Dent Res 2017;7:42-

dental practitioners (1). Despite this fact, principles of contemporary dental practice always aim for minimum intervention and retaining every functional component of the human dentition, including third molars, essentially when a third molar would serve as an abutment for a prosthetic restoration $(1,2)$ 
Literature shows that the morphological features and position of mandibular third molars always are unpredictable, and the number of roots ranges from one to four, which can show different degrees of curvatures or dilacerations, and the number of canals can reach up to six canals $(1,3$, 4). A recent report on a Jordanian subpopulation showed a wide range of root and root canal morphologies in third molars, and $8.7 \%$ of mandibular third molars were three rooted (5). Notably, the presence of an accessory disto-lingual root (radix entomolaris) is the most common presentation of three rooted mandibular molars (6, 7). However, some reports documented the occasion of three rooted mandibular first and second molars with double mesial roots (8), but the literature is limited with regards to the occasion of this anatomical variation in mandibular third molars (9).

Cone beam computed tomography (CBCT) is a three-dimensional diagnostic tool with relatively low radiation dose and reasonably high resolution and has been widely used in the endodontic field (10). This report aims to present the endodontic treatment of a three-rooted mandibular third molar with a dilacerated distal root and close approximation to the inferior alveolar canal confirmed by CBCT.

\section{Case Report}

A 26-year-old male patient was referred from an oral surgeon for root canal treatment of a left mandibular third molar (\#38). His medical history was non-contributory. The patient complained of a pain during mastication. The patient was referred for extraction, but the oral surgeon has recommended performing root canal treatment to prevent any potential injury to the inferior alveolar canal which was passing between the apices of mesial roots (Figure 1a-d). On clinical examination, the tooth \# 38 showed an occluso-distal decay. Radiographic examination showed widening of the periodontal ligament space related to a dilacerated distal root (Figure 1a). In addition, the mesial aspect of the tooth showed two separate mesial roots (Figure 1a). A CBCT scan (Veraviewepocs 3D F40, J Morita, USA) was performed to better visualize the complexity of the root morphology, and its relation to the inferior alveolar canal (Figure 1b-d). The tooth was diagnosed as symptomatic apical periodontitis.

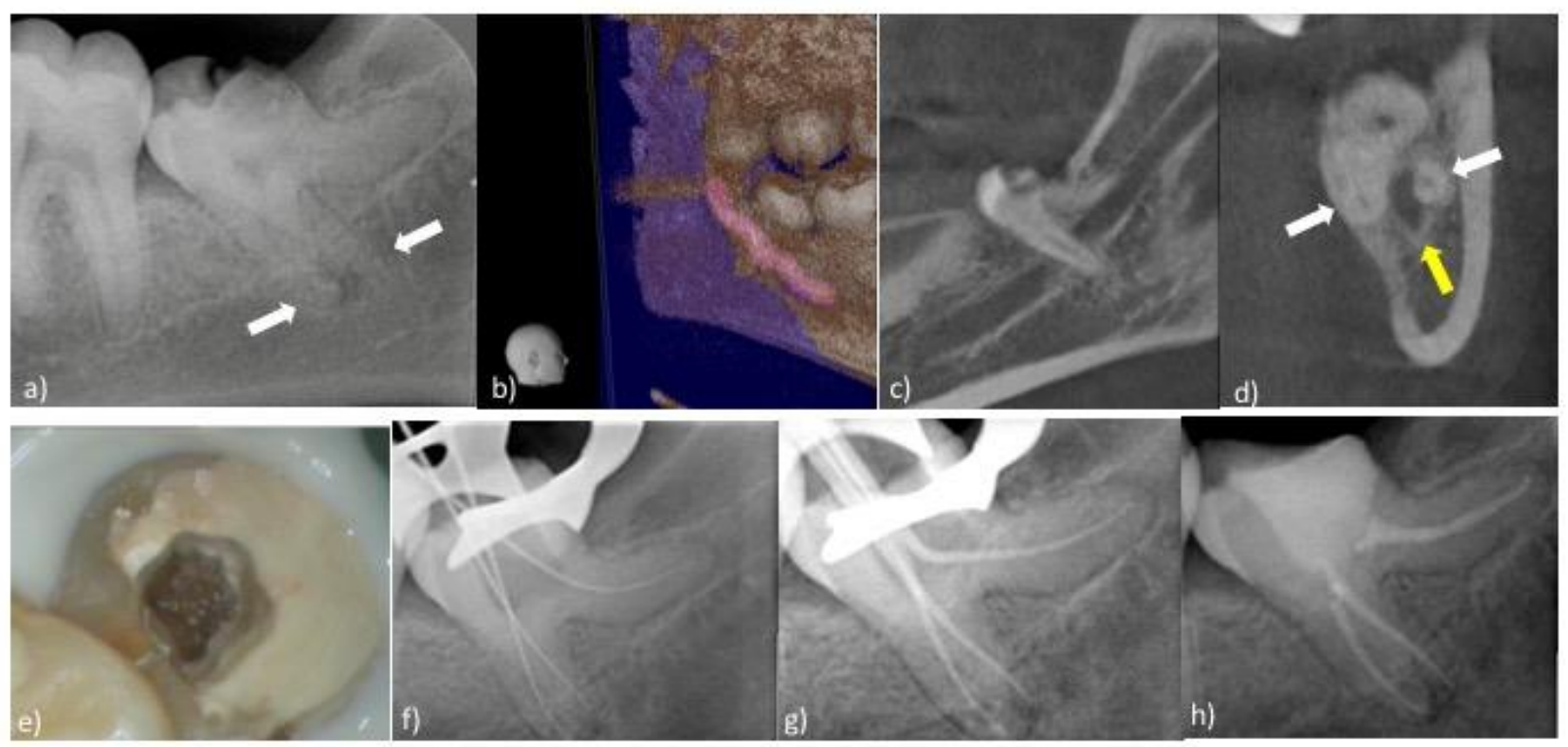

Figure 1. a) Pre-operative periapical radiograph for tooth 38 showing two mesial roots (white arrows). b) CBCT reconstruction image showing the location of the inferior alveolar canal (IAC). c) Sagittal view showing the position of the IAC. d) Axial view showing the location of the IAC (yellow arrow) between the mesial roots (white arrows). e) Access cavity preparation. f) Working length determination. g) Master gutta percha cones in place. h) Post-obturation radiographic image. 
In the first visit, the caries was removed, and a distal wall was built up using glass ionomer cement. (ChemFilTM Rock, Dentsply/De Trey, Konstanz, Germany). The rubber dam was then placed, and an access cavity was prepared under magnification (S100 OPMI pico, Carl Zeiss Jena, Germany) (Figure 1e). Glide path preparation was done using K-file \# 15 (Dentsply Sirona, Ballaigues, Switzerland). Working length determination was performed using an electronic apex locator (Root ZX mini, J Morita USA), and confirmed using a periapical radiograph (Figure 1f). According to a new system for classifying root and canal morphology (11), the tooth was classified as ${ }^{3} 38 \mathrm{MB}^{1} \mathrm{ML}^{1} \mathrm{D}^{1}$. The canals were then instrumented using a ProTaper Next (PTN) file system (Dentsply Sirona, Ballaigues, Switzerland) (mesiobuccal \# PTNX2, mesiolingual \# PTNX2, distal \# PTNX2) following manufacturer's instructions, under copious irrigation of $5 \% \mathrm{NaOCl}$. After obtaining the master gutta percha points (\# 25/0.04) (Figure 1g), the canals were obturated using cold lateral compaction technique (Figure 1h), and a resin based sealer (AH26 Dentsply-DeTrey, Konstanz, Germany) was used as the root canal sealer (Figure 1h). The access cavity was then restored with a temporary filling material (Coltosol, Coltene, USA). In the follow-up visit, the tooth was asymptomatic, and the patient was then referred back to the referring dentist for the final restoration.

\section{Discussion}

Minimum intervention is a fundamental goal of contemporary dental practice. In some clinical situations, the retention of a mandibular third molar is one valid option if the tooth is functional in the oral cavity (1). Accordingly, mandibular third molars indicated for root canal treatment should be treated thoroughly to ensure complete elimination of pulp tissues and microbial irritants thus maintaining high levels of clinical success (1).

This report aims to present the root canal treatment of a three-rooted mandibular third molar with a dilacerated distal root and close approximation to the inferior alveolar canal. Dilaceration is commonly defined as a deviation or bend of 90-degree angle or greater along the axis of the tooth or root (12). Mechanical trauma, effects of related anatomical structures and idiopathic developmental disturbances are possible etiological factors for root dilacerations $(1,12)$. In this case, the authors believe that the close approximation to the cortical bone lining of the inferior alveolar canal is the main cause for root dilaceration and splitting of the epithelial root sheath of Hertwig thus forming two mesial roots. The occasion of this developmental anomaly ranges between 3.3 to
$30.92 \%$ and can occur anywhere along the length of the root from the coronal third to the root apex (1, $12,13)$.

Despite the fact that the rubber dam is generally tolerated by patients, clinicians may face some difficulties while placing the rubber dam assembly on a mandibular third molar $(1,14)$ That's why caution should be given to keep the rubber dam away from gagging reflex trigger areas $(1,14)$. The use of apex locator in this case was beneficial to minimize additional radiographic exposures, and potential gagging reflexes $(1,14)$. In addition, determining the exact location of the minor diameter of the apical foramen was of prime importance to prevent potential mechanical irritation of the periapical area since the inferior alveolar canal lies between the mesial roots apices.

As a general rule, the use of nickel-titanium rotary file systems is not recommended in dilacerated roots, especially if the canals are narrow $(1,12)$. ProTaper Next (PTN) nickel-titanium file system was used in this molar with the dilacerated distal root because the distal canal was not narrow. This system has recently been introduced into the market, which is made from an M-Wire with a rectangular cross-section design (15). Studies demonstrated favorable mechanical properties including resistance to cyclic fatigue and torsional stresses compared to ProTaper Universal (PTU) (15, 16). This system was also chosen in this case to minimize the extrusion of debris into the periapical area. A recent report found that the PTN is associated with significantly less debris compared to PTU (17).

The use of thermoplasticized gutta percha in mandibular third molars is not a common procedure because of the lack of space for delivery tips and pluggers (1). In addition, the extrusion of thermoplasticized gutta-percha into the inferior alveolar canal has been reported (18). This justifies why the cold lateral compaction technique was the obturation method used in this case.

\section{Conclusion}

Root canal treatment procedures in mandibular third molars, which can show considerable anatomical variations, are challenging. Absolute clinical thoroughness should be undertaken while treating mandibular third molars with a close approximation to the inferior alveolar canal. 


\section{Acknowledgments}

The authors deny any conflicts of interest related to this study.

\section{References}

1. Ahmed HM. Management of third molar teeth from an endodontic perspective. Eur J Gen Dent 2012;1:148-160. Crossref

2. Plotino G. A mandibular third molar with three mesial roots: A case report. J Endod 2008;34:224-226. Crossref

3. Gulabivala K, Opasanon A, Ng YL, Alavi A. Root and canal morphology of Thai mandibular molars. Int Endod J 2002;35:56-62. Crossref

4. Sidow SJ, West LA, Liewehr FR, Loushine RJ. Root canal morphology of human maxillary and mandibular third molars. J Endod 2000;26:675-8. Crossref

5. Ahmad IA, Azzeh MM, Zwiri AM, Abu Haija MS, Diab MM. Root and root canal morphology of third molars in a Jordanian subpopulation. Saudi Endod J 2016;6:113-21. Crossref

6. Song JS, Choi HJ, Jung IY, Jung HS, Kim SO. The prevalence and morphologic classification of distolingual roots in the mandibular molars in a Korean population. J Endod 2010;36:653-7. Crossref

7. Abella $F$, Patel $S$, Durán-Sindreu $F$, Mercadé $M$, Roig $M$. Mandibular first molars with disto-lingual roots: review and clinical management. Int Endod J 2012;45:963-78. Crossref

8. Ahmed HM, Luddin N. Accessory mesial roots and root canals in mandibular molar teeth: Case reports, SEM analysis and literature review. ENDO Endod Pract Today 2012;6:195-205.

9. Sert S, Sahinkesen G, Topcu FT, Eroglu SE, Oktay EA. Root canal configurations of third molar teeth. A comparison with first and second molars in the Turkish population. Aust Endod J 2011;37:109-17. Crossref

10. Patel S, Durack C, Abella F, Shemesh H, Roig M, Lemberg K. Cone beam computed tomography in Endodontics - a review. Int Endod J 2015;48:3-15. Crossref

11. Ahmed HM, Versiani MA, De-Deus G, Dummer PM. A new system for classifying root and root canal morphology. Int Endod J 2017; 50:761-70. Crossref

12. Jafarzadeh $H$, Abbott PV. Dilaceration: review of an endodontic challenge. J Endod 2007;33:1025-30. Crossref

13. Malčić A, Jukić S, Brzović V, Miletić I, Pelivan I, Anić I. Prevalence of root dilaceration in adult dental patients in Croatia. Oral Surg Oral Med Oral Pathol Oral Radiol Endod 2006;102:104-9. Crossref

14. Ahmed HM, Cohen S, Lévy G, Steier L, Bukiet F. Rubber dam application in endodontic practice: an update on critical educational and ethical dilemmas. Aust Dent $\mathrm{J}$ 2014;59:457-63. Crossref

15. Elnaghy AM, Elsaka SE. Assessment of the Mechanical Properties of ProTaper Next Nickel-Titanium Rotary Files. J Endod 2014;40:1830-4. Crossref

16. Elnaghy AM. Cyclic fatigue resistance of ProTaper Next nickel-titanium rotary files. Int Endod J 2014;47:1034-9. Crossref
17. Silva EJNL, Carapiá MF, Lopes RM, Belladonna FG, Senna PM, Souza EM, De-Deus G. Comparison of apically extruded debris after large apical preparations by full-sequence rotary and single-file reciprocating systems. Int Endod J 2016;49:700-5. Crossref

18. Fanibunda K, Whitworth J, Steele J. The management of thermomechanically compacted gutta percha extrusion in the inferior dental canal. Br Dent J 1998;184:330-2. Crossref 